\title{
Association of bedtime usage of social media and sleep quality among governmental elementary school teachers in Jeddah city, Saudi Arabia
}

\author{
Amal Seraj Almalki ${ }^{1 *}$, Hanin Khaild Karkashanl ${ }^{2}$, Wedad Mahmoud Bardisi ${ }^{3}$, Naeema Akbar ${ }^{4}$ \\ ${ }^{1,2}$ Family Physician, ${ }^{3}$ Consultant Family Physician, ${ }^{4}$ Consultant Community Physician, ${ }^{1-3}$ The joint program of family \\ Medicine, Public Health Department, MOH, India \\ *Corresponding Author: Amal Seraj Almalki \\ Email: amalalmalki91@gmail.com
}

\begin{abstract}
Objectives: This study aimed to determine the independent association of bed time use of social media among elementary school teachers and disturbed sleep while controlling for potential covariates.

Materials and Methods: Hundred eighty-three male and 223 female teachers from Jeddah governmental schools participated in the present cross-sectional study. Pittsburgh Sleep Quality Index (PSQI) was used to assess teachers' quality of sleep. The independent $\mathrm{t}$ - test and one-way ANOVA were used to examine the linkage between sleep quality and participants characteristics, including demographics, health related behavioral characteristics, teaching related activities, associated health problems, as well as bed time use of social media. Multiple Enter linear regression analysis was performed to identify variables with higher predictive power of sleep quality.

Results: Mean \pm SD age of the sampled teachers was $39.87 \pm 6.08$. The PSQI indicated poor sleep quality (global score, mean \pm SD was $8.0 \pm 3.91$ ). Positive association was found between poor sleep and both frequency and volume of near bed time usage of social media. Regression model showed that in addition to social media use, having comorbid condition or consumption of caffeine containing drinks strongly predicted bad sleep ( $\mathrm{p}<.05)$. Considering the fact that that this is a crosssectional study design whose subjects are of middle-age group, it is probable that teachers are using social media as a means of coping with their sleeping problems rather than that social media use is disturbing their sleep.

Conclusions: The overuse of social media, having comorbid condition, and consumption of drinks containing caffeine near bed time are predictors of poor sleep, and may, as such, undermine work performance, in addition to both social and family life.
\end{abstract}

Keywords: Saudi Arabia, Social media, Sleep quality, Co-morbidities, Teachers.

\section{Introduction}

The use of social media has increased radically over the past decade, emerging as an important part of people's everyday lives, enabling them to create and maintain efficient friendships, as well as performing different activities, such as sharing videos/pictures, blogging, dating, and game playing in real-time. ${ }^{1,2}$ Users can access social media on a diverse range of platforms including: Facebook, Twitter, YouTube, Instagram, Snapchat, Google Plus, Reddit, Tumblr, Pinterest, Vine, and LinkedIn. ${ }^{3}$

To date, no consensus has been reached about the definitions or differentiation between online problematic social media use or dependence. ${ }^{1,4}$ However, researchers have suggested that both online problematic use and Internet dependence refers to poor self-regulation on using online social networking. ${ }^{4}$

There is growing evidence to propose the association between the use of electronic social media and sleep disorders. ${ }^{5-8}$ The use of social media near bedtime has been known to influence poor sleep, either due to increased anxiety or depression at bedtime, as a consequence of negative interactions experience or owing to the disturbance of normal sleep-wake cycles and circadian rhythms attributed to the emission of short-wavelength-enriched light from several devices used for social networking. ${ }^{9-11}$

Sleep is an essential component of healthy life and plays a critical role in various body functions, including metabolism, appetite regulation, immunehormonal, as well as cardiovascular systems. ${ }^{12}$ Good 
quality sleep is described as being of a sufficient duration, appropriate timing, and regularity. ${ }^{13}$ Sleep disorders may affect the body in myriad ways. For example, the short-term consequences of sleep disorder include somatic pain, emotional and mood disorders, with generally reduced quality of life, while long-term ramifications may include dyslipidemia, cardiovascular disease, hypertension, metabolic disorders such as type 2 diabetes mellitus, as well as colorectal cancer. ${ }^{14}$

The aim of this study was to investigate the correlation between use of social media near bed time and quality of sleep among teachers working at the general governmental elementary schools in Jeddah, Saudi Arabia.

\section{Materials and Methods}

\section{Sampling}

The present study was conducted among 406 teachers working at general governmental elementary schools in Jeddah, Saudi Arabia during the calendar year, 2019. By adopting the multistage clustering sampling approach and applying the Probability Proportional to Size technique, 183 males and 223 females were added into the study.

After obtaining approval from the Ethics and Scientific Committee, a self-administered questionnaire was distributed among the participants after obtaining their verbal consent.

The major areas included in the questionnaire included (1) demographic data, and health-related behavioral characteristics, (2) school-related activities, (3) associated health problem, (4) bed time use of social media, and (5) quality of sleep.

Degree of engagement in social media was measured by two variables; the first variable reflects the duration of social media engagement, as represented in three groups $1=<30 \mathrm{~min} ; 2=30-60$ $\min$; and $3=>60 \mathrm{~min}$. Meanwhile the second variable reflects frequency of social media use, which was measured by the number of visits to social media platforms per week. The frequency variable was estimated by asking participants to indicate the frequency with which they visited or used each of the seven most popular social media platforms: WhatsApp, Snapchat, Twitter, Facebook, Instagram,
Pinterest, and YouTube. This variable was represented in three groups: $1=$ use the platform less than once/week; 2 = 2-3 days a week; and $3=$ daily use. For each participant, the degree of engagement in social media use was calculated by adding the sum of his/her answer (duration and frequency of platform visits). This yielded a minimum score of 2 (use the platform less than once /week for less than $30 \mathrm{~min}$ ), and a maximum score of 6 (daily use of platform for more than $60 \mathrm{~min}$ ). This score was further dichotomized into two groups defined as normal use and overuse with cut-off level of 4 .

Sleep quality was examined using the PSQI (Buysse, Rey- nolds III, Monk, Berman \& Kupfer, 1989) that measures subjective sleep quality during the preceding 1-month period. It comprises of 19 questions grouped into scores with seven components. These components include (1) perceived sleep quality; (2) sleep latency (how long it takes to fall asleep); (3) sleep duration; (4) sleep efficiency (how long a person is asleep as compared to their time in bed); (5) sleep disturbances (i.e., noise, temperature, pain, nocturia); (6) sleep medications; and (7) daytime dysfunction (sleepiness, concentration). The component scores were then added to a global PSQI score with a range of 0 to 21, with higher scores indicative of worse sleep quality. PSQI scores of above 5 were taken as abnormal. ${ }^{15,16}$ Assessment of the clinometric and clinical properties of the PSQ led to acceptable measures of internal homogeneity, reliability, and validity. ${ }^{16}$

\section{Data entry and analysis}

Descriptive statistics were presented as mean \pm standard deviation, whereas categorical variables were presented in the form of frequency and percentages. Bivariate and multivariate analysis was performed for participants who completed all components of sleep quality score.

The independent t- test and one-way ANOVA test were used to examine the associations between sleep quality score and participants' personal characteristics (gender, marital status, children, years of experience, school classroom activities, and comorbid conditions). Post hoc analysis was performed to identify the groups that showed difference in the ANOVA test. 
Multiple Enter linear regression analysis was performed to identify the variables with higher predictive power of sleep quality. In addition, potential confounding variables were selected from the list of independent variables. Testing data for collinearity concerning the variables predicting sleep quality indicated that multicollinearity was not a concern having, whereas VIF $<10$ and Tolerance 0.1. variables with positive Beta Coefficients were kept in the final regression model. The assumption of normality for the residue of the regression model and the assumption of error was met (Durbin-Watson=1.71). An analysis of standard residuals was carried out, as per which the data contained no outliers (Std. Residual Min $=3.15$, Std. Residual Max =12.77). Correlation analyses were two-sided, and a significant level was considered by.05 error for all analyses.

Statistical analyses were conducted using the Statistical Package for the Social Sciences (SPSS), version 22.0 (IBM Corporation, Armonk, United States)

\section{Results}

\section{Study group characteristics}

A total of 406 elementary school teachers participated in this study. The mean age $\pm \mathrm{SD}$ was $39.87 \pm 6.08$ (Minimum=15, Maximum=58). Hundred eighty-three (45.1\%) were male and 223 (54.9\%) were female. The majority of participants were married (86.2\%), 7.4\% were single, and $6.2 \%$ were either divorced or widowed. High percentage $(86.5 \%)$ had children, whereas the mean number of children was $3.49 \pm 1.48$. Nearly $50 \%$ of the teachers spent more than 5 years in teaching, $29.7 \%$ spent between $1-5$ years, and $13.1 \%$ spent less than one year. More than half of teachers (53.7\%) reported having class assignments between 16-24/ week, 27.8\% had 9-15 classes/week, and 12.3\% had less than 9 classes/ week. Similarly, around two third $(67.8 \%)$ had extra class activities. A high number of teachers complained of at least one health-related problem (35.5\%) (Table 1).

\section{Near bed time use of Social media}

A large proportion of teachers $(79.7 \%)$ reported that they visit social media platforms on a daily basis; however, a lower proportion $(22.6 \%)$ engaged with the platform for more than one hour, whereas $48.8 \%$ remained for less than 30 minutes. Classifying participants based on the extent of social media use showed that $51.4 \%$ were normal users, whereas $48.6 \%$ were over users (Table 2). The type of social platform visited by participants is illustrated in Fig. 1.

\section{Sleep quality}

Of all 406 participants, it was found that $71.2 \%$ (n $=289$ ) completed all components of the PSQI, whereas the Mean \pm SD for the global score was $8.0 \pm 3.91$. The different mean scores of sleep quality among teachers in accordance with their characteristics is depicted in Table 3. Near bed time consumption of caffeine containing drinks, presence of comorbid condition and frequency, as well as the duration of social media usage were significantly associated with sleep quality $\mathrm{P}<.05$.

Table 4 illustrates that the mean score of global sleep quality among excessive users of social media was significantly poorer than normal users $\mathrm{P}<.05$. Different components of sleep quality revealed different significant levels, while sleep latency score was the poorest components, followed by the score of sleep duration and sleep disturbances. On the other hand, the use of sleeping medication score was found to be the best. Type of test of association between users of different platforms was not significantly related with sleep quality $\mathrm{p}>.05$.

\section{Covariates}

According to the findings of multiple linear regression, sleep quality was significantly predicted by four variables: health problems, consumption of drinks containing caffeine, sex and the usage of social media before bed time. Table 5 shows a stronger standardized Beta-value for having health problem and caffeine containing drinks, as well as smaller Beta-value for sex and the usage of social media before bed time. Importantly, the relatively small $\mathbf{r}^{2}(0.18)$ indicated that these variables predicted only $18 \%$ of sleep quality. 
Table 1: Demographic and work-related characteristic of teachers using social media in Jeddah elementary schools

\begin{tabular}{|c|c|c|}
\hline Variable & $\mathbf{N}$ & $\%$ \\
\hline Age $(n=350)($ Mean \pm SD $)$ & \multicolumn{2}{|c|}{$39.87 \pm 6.08($ Minimum $=15$ Maximum $=58)$} \\
\hline \multicolumn{3}{|l|}{ Gender $(n=406)$} \\
\hline Males & 183 & 45.1 \\
\hline Females & 223 & 54.9 \\
\hline \multicolumn{3}{|l|}{ Marital Status $(n=405)$} \\
\hline Married & 350 & 86.2 \\
\hline Single & 30 & 7.4 \\
\hline Divorced or Widow & 25 & 6.2 \\
\hline \multicolumn{3}{|l|}{ Have children $(n=403)$} \\
\hline Yes & 351 & 86.5 \\
\hline No & 52 & 12.8 \\
\hline Number of children & \multicolumn{2}{|c|}{$($ Mean \pm SD) $3.49 \pm 1.48($ Minimum= 1 Maximum $=9)$} \\
\hline \multicolumn{3}{|l|}{ Years spent in the educational career $(\mathrm{n}=399)$} \\
\hline$>5$ & 353 & 57.2 \\
\hline $1-5$ & 40 & 29.7 \\
\hline$<1$ & 6 & 13.1 \\
\hline \multicolumn{3}{|l|}{ Number of classes per week $(n=381)$} \\
\hline $16-24$ & 218 & 53.7 \\
\hline $9-15$ & 113 & 27.8 \\
\hline$<9$ & 50 & 12.3 \\
\hline \multicolumn{3}{|l|}{ Out classroom activities $(\mathrm{n}=385)$} \\
\hline Yes & 261 & 67.8 \\
\hline No & 124 & 32.2 \\
\hline \multicolumn{3}{|l|}{$\begin{array}{l}\text { Near bed time intake of caffeine containing } \\
\text { drinks }(n=393)\end{array}$} \\
\hline Never & 62 & 15.8 \\
\hline Rarely & 111 & 27.3 \\
\hline Occasionally & 135 & 34.4 \\
\hline Usually & 85 & 21.6 \\
\hline \multicolumn{3}{|l|}{ Sport playing before bed time $(n=396)$} \\
\hline Yes & 157 & 39.6 \\
\hline No & 239 & 60.4 \\
\hline \multicolumn{3}{|l|}{ Current smoker $(\mathrm{n}=396)$} \\
\hline Yes & 109 & 27.5 \\
\hline No & 287 & 72.5 \\
\hline \multicolumn{3}{|l|}{ Presence of comorbid condition* $(n=391)$} \\
\hline Yes & 139 & 35.5 \\
\hline No & 252 & 64.5 \\
\hline
\end{tabular}

* Comorbid condition =Type 2 diabetes mellitus, High blood pressure, Hypercholesteremia, Arthritis, Bronchial Asthma, Psychological problem, food regurgitation, and sleeping Apnea 
Table 2: Frequency and duration of using social media near bed time among elementary school teachers in Jeddah $(\mathrm{n}=381)$.

\begin{tabular}{|c|c|c|}
\hline Variable & N & \% \\
\hline Frequency of visiting social media platforms & & \\
Daily & 315 & 79.7 \\
2-3/week & 60 & 15.2 \\
<once/ week & 20 & 5.1 \\
\hline Time spent using social media & & \\
30-60 min & 186 & 48.8 \\
>60 min & 109 & 28.6 \\
& 86 & 22.6 \\
\hline Degree of social media use & & \\
Normal use & 196 & 51.4 \\
Over use & 185 & 48.6 \\
\hline
\end{tabular}

Table 3: Comparison of the sleep quality score among elementary school teachers based on personal characteristics

\begin{tabular}{|c|c|c|c|c|c|}
\hline \multirow{2}{*}{ Variable } & \multicolumn{2}{|c|}{ Sleep quality score } & \multirow{2}{*}{ df } & \multirow{2}{*}{ Test value } & \multirow{2}{*}{$P$ value } \\
\hline & Mean & SD & & & \\
\hline Age group & & & \multirow{5}{*}{3,254} & \multirow{5}{*}{$0.30 *$} & \multirow{5}{*}{0.82} \\
\hline$<30$ & 7.00 & 3.71 & & & \\
\hline $30-39$ & 8.20 & 3.91 & & & \\
\hline $40-49$ & 8.09 & 4.00 & & & \\
\hline$\geq 50$ & 8.07 & 4.62 & & & \\
\hline Gender & & & \multirow{3}{*}{287} & \multirow{3}{*}{$1.19 * *$} & \multirow{3}{*}{0.24} \\
\hline Males & 7.72 & 3.90 & & & \\
\hline Females & 8.27 & 3.93 & & & \\
\hline Marital Status & & & \multirow{4}{*}{2,286} & \multirow{4}{*}{$1.17 *$} & \multirow{4}{*}{0.31} \\
\hline Single & 7.27 & 4.61 & & & \\
\hline Married & 7.97 & 3.84 & & & \\
\hline Divorced /Widow & 9.1 & 4.05 & & & \\
\hline Have kids & & & \multirow{3}{*}{285} & \multirow{3}{*}{$1.35 * *$} & \multirow{3}{*}{0.180} \\
\hline Yes & 8.12 & 3.91 & & & \\
\hline No & 7.17 & 4.07 & & & \\
\hline Years of teaching & & & \multirow{4}{*}{2,282} & \multirow{4}{*}{$1.21 *$} & \multirow{4}{*}{0.30} \\
\hline$<1$ & 9.80 & 6.22 & & & \\
\hline $1-5$ & 7.15 & 4.60 & & & \\
\hline$>5$ & 8.08 & 3.81 & & & \\
\hline Number of classes per week & & & \multirow{4}{*}{2,272} & \multirow{4}{*}{$1.75^{*}$} & \multirow{4}{*}{0.338} \\
\hline$<9$ & 8.77 & 3.36 & & & \\
\hline $9-15$ & 7.43 & 4.08 & & & \\
\hline $16-24$ & 8.16 & 3.94 & & & \\
\hline Sport playing near bed time & & & \multirow{3}{*}{256} & \multirow{3}{*}{$1.36 * *$} & \multirow{3}{*}{0.174} \\
\hline Yes & 7.56 & 3.56 & & & \\
\hline No & 8.20 & 4.06 & & & \\
\hline
\end{tabular}




\begin{tabular}{|c|c|c|c|c|c|}
\hline Current smoker & 8.39 & 3.78 & 282 & $1.21 * *$ & 0.227 \\
Yes & 7.76 & 3.90 & & & \\
No & & & & & \\
\hline Caffeine consumption before bed & 6.52 & 3.47 & & & \\
Never & 7.24 & 3.79 & 3,279 & $5.36^{*}$ & 0.001 \\
Rare & 8.56 & 3.64 & & & \\
Occasionally & 8.90 & 4.12 & & & \\
Usually & & & & & \\
Comorbid condition & 9.15 & 4.40 & 282 & $4.30 * *$ & \\
Yes & 7.20 & 3.34 & & & \\
No & & & & & \\
\hline Frequency of using social media & 5.73 & 3.58 & \multirow{2}{*}{2,281} & $3.08 *$ & \\
<once/ week & 7.19 & 3.68 & & & \\
2-3/week & 8.19 & 3.90 & & & \\
daily & & & & & \\
\hline Duration of using social media & 7.46 & 3.33 & 2,273 & $3.08 *$ & \\
30-60 min & 8.41 & 3.95 & & & \\
\hline 60 min & 8.81 & 4.63 & & & \\
\hline
\end{tabular}

*One-way ANOVA test $\mathrm{F}$

** Independent T-test

Table 4: Relation between level of use of social media, sleep quality score and their different components among elementary school teachers.

\begin{tabular}{|l|c|c|c|c|c|c|c|c|}
\hline \multirow{2}{*}{ Sleep Component } & \multicolumn{2}{l|}{ Overall Score } & \multicolumn{2}{l|}{ Normal use } & \multicolumn{2}{l|}{ Over use } & \multirow{2}{*}{ P value } \\
\cline { 2 - 9 } & Mean & SD & Mean & SD & Mean & SD & & \\
\hline Global Sleep quality Score & 8.00 & 3.92 & 7.50 & 3.40 & 8.60 & 4.23 & 2.40 & 0.02 \\
\hline Subjective sleep quality score & 0.74 & 0.76 & 0.66 & 0.72 & 0.85 & 0.80 & 2.3 & 0.019 \\
\hline Sleep latency Score & 2.55 & 1.65 & 2.26 & 1.48 & 2.88 & 1.76 & 3.61 & 0.000 \\
\hline Sleep duration score & 1.65 & 0.96 & 1.60 & 0.94 & 1.71 & 0.99 & 1.14 & 0.24 \\
\hline Sleep efficiency score & 0.61 & 0.85 & 0.48 & 0.72 & 0.77 & 0.95 & 3.40 & 0.001 \\
\hline Sleep disturbances score & 1.39 & 0.65 & 1.38 & 0.62 & 1.39 & 0.67 & 1.62 & 0.87 \\
\hline Use of sleeping medication score & 0.53 & 0.94 & 0.50 & 0.90 & 0.61 & 1.00 & 1.00 & 0.32 \\
\hline Daytime dysfunction score & 0.80 & 0.83 & 0.86 & 0.86 & 0.75 & 0.80 & 1.3 & 0.21 \\
\hline
\end{tabular}

\section{Discussion}

The proliferation of social media among Saudi society, evidenced in the fact that two thirds of the country's population is now on active social media, has raised the issue of the problematic use of social media. ${ }^{17}$ One particular concern is the use of social media among school teachers, who need to have good sleep quality and quantity to be able to adequately accomplish their daily teaching job.
This study focused on both the frequency and volume i.e. the duration of use of social media. Findings of frequency use showed comparable results with the Saudi statistics, given that $79.7 \%$ of the study participants visits social media platforms on a daily basis; however, most of them spend less than 30 $\mathrm{min} /$ visit.

A higher proportion of social media users preferred WhatsApp and Snap Chat over other platforms, as these two social media types are most 
popular in Saudi Arabia, ${ }^{17}$ serving as an appropriate means for users to engage with friends and family members quickly, efficiently, and in real-time.

In the study sample, the mean global sleep quality was 9.00, indicating poor sleep, since a global PSQI score above 5 is highly sensitive and specific in distinguishing poor sleepers from good sleepers. ${ }^{18,19}$

Good sleep is important for self-satisfaction and for healthy productive life; however, three important components of sleep quality were rated as poor among participant teachers: Sleep latency score, sleep duration score and sleep disturbances score. Sleep latency (the time period from the state of wakefulness to sleep) were rated as the poorest (2.55). This study revealed that sleep quality was consistently and substantially affected by both frequency and duration of using social media.

The sample also showed that around half of the teachers grouped as excessive users of social media, which was significantly associated with poor sleep. This relationship was equivalently reported by other countries. $^{3,5-8,20,21}$

In addition to the overuse of social media as an indicator of poor sleep quality, having comorbid condition and consumption of coffee containing drinks near bed time was found to be strong predictors of poor sleep as well.

Age, sex, social status, having kids and workrelated conditions were not associated with sleep quality. The fact that this study targeted higher age group of population than most studies in the literature that usually involves teenagers as well as young adults, ${ }^{3,415,22-24}$ underpinned the importance of new adult related predictors on sleep quality.

Since this study was based on a cross-sectional design, no conclusions about cause and effects relation can be reached at. Considering the strong association between poor sleep quality, having health problems and consumption of caffeine containing drinks before bed time, it is possible that the negative effects of social media use on sleep, could be attributed to the fact that teachers use social media as a means of coping with their sleeping problems rather than that the use of social media is disturbing sleep. Such association was similarly elucidated in studies associating sleep disturbance and use of social media., ${ }^{3,21}$ Similarly, the strong association between teachers having comorbid condition and poor sleep may also be attributed to the long-term consequences of poor sleep such as dyslipidemia, cardiovascular disease, hypertension, and type 2 diabetes mellitus. ${ }^{14}$ However; it is important to note that the test of collinearity of social media use, having comorbid condition, and consumption of drinks containing caffeine in the final regression model within the existing study proved that each variable predicted sleep quality independently.

This study's limitations were the inadequate assessment of other confounders, including socioeconomic status, and psychological conditions such as depression and anxiety disorder. In addition, the cross-sectional design is inappropriate for determining the cause effect relation-ship, which is why longitudinal studies examining detailed causal relationship are required.

\section{Conclusion}

In summary, the overuse of social media, having comorbid condition, as well as consumption of drinks containing caffeine before bed time are predictors of poor sleep, and as such, may undermine work performance as well as social and family life. Given the fact that social media use is becoming an important lifestyle behavior for both sex of all age groups, it should be noted as a major determinant of sleep quality when establishing strategies for sleep hygiene.

\section{Acknowledgment}

The authors express their gratitude to the employees of Ministry of Education for their cooperation and support, and Dr. Ahmad Alawi, and Dr. Waleed al Zahrani, Ms. Khirah al Malki, as well as Ms. Ebtisam al Zahrani for data collection pertaining to this study.

\section{Source of Funding}

None.

\section{Conflict of Interest}

None.

\section{References}

1. Bányai F, Zsila Á, Király O, Maraz A, Elekes Z, Griffiths 
MD, et al. Problematic social media use: Results from a large-scale nationally representative adolescent sample. PLoS One 2017;12(1):17-20.

2. Altuwairiqi M, Jiang N, Ali R. Problematic attachment to social media: Five behavioural archetypes. Int J Environ Res Public Health 2019;16(12):1-46.

3. Levenson JC, Shensa A, Sidani JE, Colditz JB, Primack BA. The association between social media use and sleep disturbance among young adults. Prev Med (Baltim) [Internet]. 2016;85:36-41. Available from: http://dx.doi.org/10.1016/j.ypmed.2016.01.001

4. Martínez-Ferrer B, Moreno D, Musitu G. Are adolescents engaged in the problematic use of social networking sites more involved in peer aggression and victimization? Front Psychol 2018;9(801):1-13.

5. Munezawa T, Kaneita Y, Osaki Y, Kanda H, Minowa M, Suzuki K, et al. The Association between Use of Mobile Phones after Lights Out and Sleep Disturbances among Japanese Adolescents: A Nationwide Cross-Sectional Survey. Sleep 2011;34(8):1013-20.

6. Brunborg GS, Mentzoni RA, Molde H, Myrseth H, Skouverøe KJM, Bjorvatn B, et al. The relationship between media use in the bedroom, sleep habits and symptoms of insomnia. J Sleep Res 2011;20(4):569-75.

7. Hysing M, Pallesen S, Stormark KM, Jakobsen R, Lundervold AJ, Sivertsen B. Sleep and use of electronic devices in adolescence: Results from a large populationbased study. BMJ Open 2015;5(1):1-7.

8. Villanti AC, Johnson AL, Ilakkuvan V, Jacobs MA, Graham AL, Rath JM. Social media use and access to digital technology in US Young Adults in 2016. J Med Internet Res 2017;19(6):1-25.

9. Seabrook EM, Kern ML, Rickard NS. Social Networking Sites, Depression, and Anxiety: A Systematic Review. JMIR Ment Heal 2016;3(4):e50.

10. Levenson JC, Shensa A, Sidani JE, Colditz JB, Primack BA. Social media use before bed and sleep disturbance among young adults in the United States: A nationally representative study. Sleep 2017;40(9):4-11.

11. Woods H, Scott H. \#Sleepyteens: Social media use in adolescence is associated with poor sleep quality, anxiety, depression and low self-esteem. - PubMed - NCBI. $J$ Adolesc 2016;51:41-9.

12. Watson NF, Badr MS, Belenky G, Bliwise DL, Buxton OM, Buysse D, et al. Joint Consensus Statement of the American Academy of Sleep Medicine and Sleep Research Society on the Recommended Amount of Sleep for a Healthy Adult: Methodology and Discussion. J Clin Sleep Med 2015;11(8):931-52.

13. Watson NF, Badr MS, Belenk G, Bliwise DL. Recommended amount of sleep for a healthy adult. Am Acad Sleep Med Sleep Res Soc 2015;38(6):843-4.
14. Medic G, Wille M, Hemels ME. Short- and long-term health consequences of sleep disruption. Nat Sci Sleep 2017;9:151-61.

15. Demirci K, Akgönül M, Akpinar A. Relationship of smartphone use severity with sleep quality, depression, and anxiety in university students. $J$ Behav Addict 2015;4(2):85-92.

16. Morris JL, Rohay J, Chasens ER. Sex Differences in the Psychometric Properties of the Pittsburgh Sleep Quality Index. J Women's Heal 2018;27(3):278-82.

17. Saudi Arabia Social Media Statistics 2019 (Infographics) GMI Blog [Internet]. 2019 [cited 2019 Nov 13]. Available from: https://www.globalmediainsight.com/blog/saudiarabia-social-media-statistics/

18. Casement MD, Harrington KM, Miller MW, Resick. PA. Associations between Pittsburgh Sleep Quality Index Factors and Health Outcomes in Women with Posttraumatic Stress Disorder. Sleep Med 2012;13(6):7528.

19. Buysse DJ, Reynolds CF, Monk TH, Berman SR, Kupfer DJ. The Pittsburgh sleep quality index: A new instrument for psychiatric practice and research. Psychiatry Res 1989;28(2):193-213.

20. Mohammadbeigi A, Absari R, Valizadeh F, Saadati M, Sharifimoghadam S, Ahmadi A, et al. Sleep quality in medical students; the impact of over-use of mobile cellphone and social networks. J Res Health Sci 2016;16(1):46-50.

21. Tavernier R, Willoughby T. Sleep problems: Predictor or outcome of media use among emerging adults at university? J Sleep Res 2014;23(4):389-96.

22. Yonker LM, Zan S, Scirica C V, Jethwani K, Kinane TB. "Friending" teens: Systematic review of social media in adolescent and young adult health care. J Med Internet Res 2015;17(1):e4.

23. Thomée S, Härenstam A, Hagberg M. Computer use and stress, sleep disturbances, and symptoms of depression among young adults - a prospective cohort study. BMC Psychiatr 2012;12(176).

24. Kawabe K, Horiuchi F, Oka Y, Ueno S. Association between Sleep Habits and Problems and Internet Addiction in Adolescents. Psychiatr Invest 2019;16(8):581-7.

How to cite this article: Almalki AS, Karkashanl HK,
Bardisi WM, Akbar N, Association of bedtime usage of
social media and sleep quality among governmental
elementary school teachers in Jeddah city, Saudi Arabia. J
Community Health Manag 2019;6(4):119-26.

